\title{
Application of Green Concept in Energy-Saving Design of Building HVAC System
}

\author{
Shengjie Guo*, Shi Wang \\ College of Civil Engineering and Water Resources, Heilongjiang Bayi Agricultural University, Daqing, 163319, China
}

DOI: $10.36348 /$ sjet.2020.v05i07.001

| Received: 23.06.2020 | Accepted: 01.07.2020 | Published: 05.07.2020

*Corresponding author: Shengjie Guo

\section{Abstract}

With the continuous progress of the society, the problem of energy consumption is increasingly prominent, green energy saving is gradually promoted. At present, the combination of green building concept in architectural design has become the common focus of contemporary architectural industry. HVAC is a key link in building energy consumption, which has attracted much attention in recent years. The application of green and energy-saving concepts in building heating and air-conditioning design can not only reduce energy consumption and cost, but also improve operating efficiency, safety and comfort. On the other hand, it not only protects the balance and development of the environment, but also realizes the healthy and sustainable development of air conditioning. It can be said that the green concept in the whole HVAC design of the application is very significant.

Keywords: Green concept; HVAC; Energy-saving design; application.

Copyright @ 2020: This is an open-access article distributed under the terms of the Creative Commons Attribution license which permits unrestricted use, distribution, and reproduction in any medium for non-commercial use (NonCommercial, or CC-BY-NC) provided the original author and source are credited.

\section{INTRODUCTION}

With the deepening of the modernization process, people's living standards continue to improve, modern design also continues to develop. The architectural needs of modern residents are also changing. From comfort to modern humanistic design, many buildings meet the housing needs of modern residents and the national sustainable development strategy. The most significant feature of green buildings is that they have low energy consumption and low emissions. They can meet people's living conditions and make rational use of resources. Among them, energysaving technology is particularly important for building heating, ventilation and air conditioning system, which is an important design if environmental factors are considered. Humanization is the basic requirement of modern building market. The energy-saving technology design of HVAC system with green concept meets the needs of more consumers, and the more practical and environmentally sustainable concept promotes the ecological construction of buildings and the improvement of the overall level $[1,2]$.

The importance of green concept in energy-saving design of building HVAC system

The HVAC system is almost in line with the necessary configuration of all buildings in China today. HVAC to ensure that the air-conditioning system running route, with its stability. In addition to further reducing the probability of subsequent failures, reducing unnecessary energy consumption is also an important goal. Therefore, the construction of HVAC system in buildings should do a good job in energy conservation design. In the construction of HVAC system, the application of green concept has become an important means in the energy-saving design of building HVAC system. Its specific functions are as follows [3]:

On the one hand, the green and energy-saving design of building HVAC system can control the energy consumption of the original system and play a prominent role in the improvement and optimization of the original system. In the past, building heating and air conditioning systems have been running with high energy consumption, with much of the energy wasted. Therefore, preventing this kind of waste effectively has become an important task of green energy saving design. Construction industry is a prominent energy consumption industry, air-conditioning system is an important part of energy consumption. If green energysaving design can be realized, a large number of energy saving and utilization will effectively alleviate the problem of energy shortage in China [4]. 
On the other hand, the green concept has been applied in the energy-saving design of building temperature control air conditioning system, which can better realize the role of environmental protection. For example, the active introduction and application of some advanced green materials in the air conditioning system can optimize the operation effect of the ventilation and air conditioning system, improve the effect of indoor environmental protection, and create more comfortable living conditions. Compared with the traditional HVAC design, the green concept of HVAC design can increase the proportion of renewable energy and achieve environmental protection effect, with more obvious green effect. The following is the key design diagram of HVAC engineering [5]:

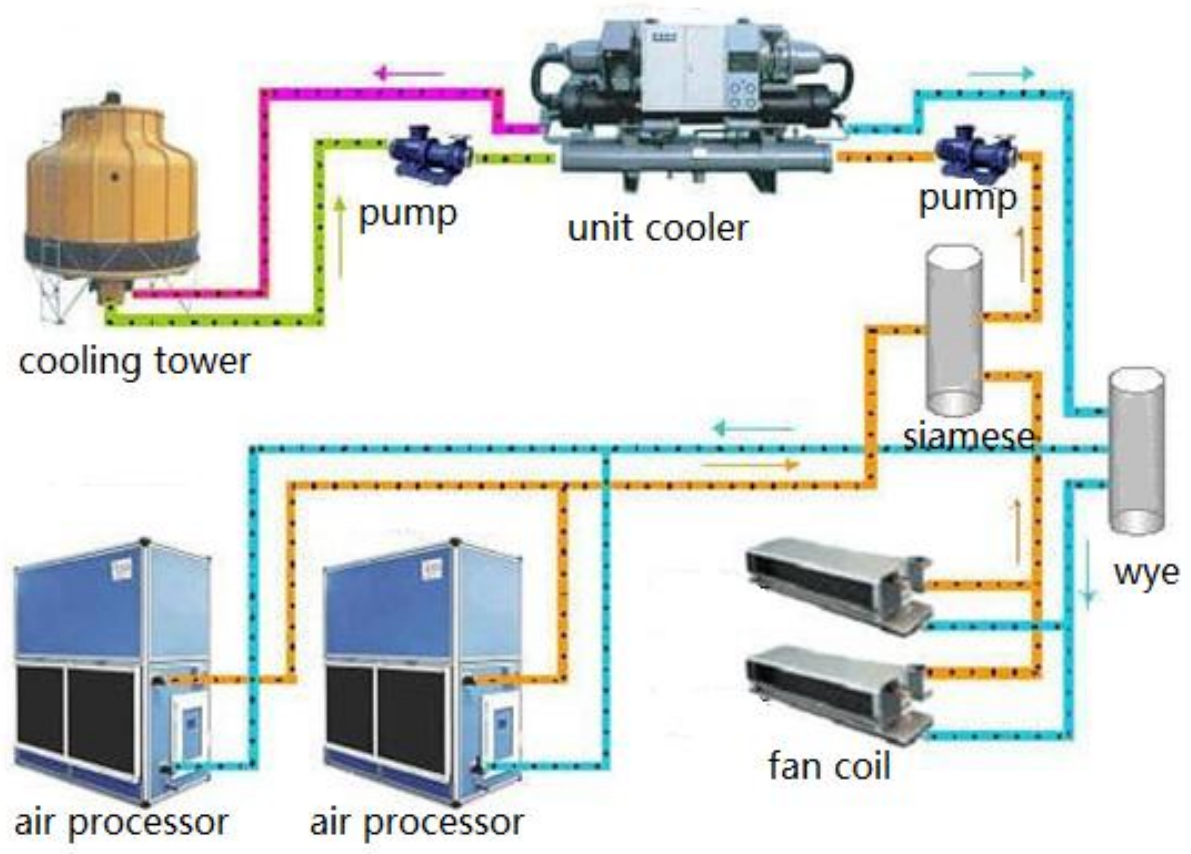

Application of green concept in energy-saving design of building HVAC system

\section{Proper choice of heat source}

Building HVAC energy saving design to reflect the green concept, often from the source. If we can choose relatively clean and efficient energy sources, we will surely contribute to environmental protection with effective energy conservation. At present, the heating system in northern China is basically central heating, and the cooling source is basically electric energy. Heating in southern China is mostly powered by electricity. The application of this method not only causes serious energy loss, but also causes environmental pollution in the operation of power system, which is the important focus of the application of green concept. In addition to the central heating system in the northern region, we should also take the necessary measures to choose the heat source, choose the local conditions, and select the building type and use characteristics based on the corresponding heat source analysis, such as air source heat pump, ground heat pump, solar energy, etc.

It has been found that the underground heat pump is economical and can effectively control air pollutants. Most importantly, buildings can significantly improve the quality of the indoor environment. Therefore, the energy-saving design of hot air air conditioning can be based on the actual situation of the hot air air conditioning competition field, a reasonable choice of heat source, scientific reduction of environmental pollution, improve economic benefits.

\section{Make the most of the natural wind}

Under the green concept, the energy-saving design of building HVAC system should also pay full attention to the use of natural wind. If natural ventilation can be coordinated during the operation of HVAC, the operating pressure of HVAC can be effectively alleviated and the ideal energy saving effect can be achieved. On this basis, designers generally need to focus on the investigation of understanding the local natural wind conditions. Combined with the proper layout of the existing door and window structure, the effect of promoting natural ventilation is stronger, and the internal space of the building for heat and humidity removal is better made, which will reduce the energy consumption of the air conditioning system. This also requires the air conditioning designer to coordinate with the design personnel of the main structure of the building project to coordinate the natural ventilation direction and wind speed to ensure a stronger natural ventilation effect. In particular, the circulation resistance structure of air should be considered comprehensively. In addition, air quality should be fully considered in the design of naturally ventilated 
buildings, and a naturally ventilated building can be built with appropriate configuration to have a fresh air system.

\section{Select Elements and Tubing}

In order to prevent and control energy consumption loss, designers should pay attention to optimize the design to reflect the powerful energy utilization efficiency and reduce heat loss. In the meantime, the choice that the building such as conduit warms up a system, should notice heat insulation effect commonly, avoid producing energy loss. In addition, if the high performance steel pipe is optimized according to different media and use environment, the subsequent energy consumption problem can be effectively avoided. To strictly control the key heating and cooling elements of HVAC system, improve the operating efficiency of these key parts and further improve the heat exchange efficiency, it is necessary to introduce and apply some advanced technologies. In some key areas of HVAC system, the envelope structure can be added to ensure its stronger operation performance.

\section{Applied frequency conversion technology}

Green building layout and energy-saving design of air conditioning system should also pay attention to the application of flexible and advanced technology, such as the application of frequency conversion technology, which needs high attention. At present, heating and power regulator systems are widely used, but the application effect is not uniform, it is difficult to play a strong energy efficiency. Power conversion technologies are application-centric and through further research there is a greater need to improve energy efficiency. In the electrical construction of air-conditioning system applications, the assistance of automation technology is generally considered, which is reflected in the application of advanced electronic technology and the reduction of load in the air-conditioning system in most buildings. The designer shall reasonably install the temperature and humidity induction device in the HVAC system and formulate scientific and reasonable control procedures to make the operation of the air-conditioning system more accurate and eliminate unnecessary loads.

Frequency conversion technology is an early green energy saving technology applied in HVAC. This can not only save resources effectively, but also improve the efficient use of resources, and play a role in protecting the environment and maintaining the balance of nature and ecology. Therefore, frequency conversion technology in HVAC design can show the green energy-saving effect, play a good role in the promotion. The application of frequency conversion technology makes a good adjustment to the internal environment of buildings, which is mainly reflected in two aspects: first, when the natural light intensity is enhanced, the adjustment unit of variable frequency strip also increases with the increase of lift output heat. Second, when there are more people in the building, starting the fan output heat automatically increases. It can be seen that the application of frequency conversion technology can effectively reduce energy consumption and achieve the effect of energy saving. The advantages of this technology are as follows: first, self-regulation through temperature change can not only meet users' needs, but also improve users' use efficiency and energy saving effect. Second, all energy-consuming facilities can be independently controlled, free from the influence and interference of any other factors.

\section{Reasonable application of cold storage technology}

The energy-saving design of HVAC system under the concept of green building can flexibly use energy-saving technology and effectively adjust the energy applied by itself. In the case of refrigeration, for example, water freezes to form ice at the right time and is then cooled by melting ice. The application of low temperature technology not only effectively alleviates the power supply pressure of peak power consumption, but also reflects the strong energy efficiency. Relatively speaking, the energy consumption is low, and does not affect the indoor temperature regulation effect.

\section{Application of heat energy recovery technology}

Waste heat refers to the energy that is not fully utilized by the energy resource utilization equipment under certain economic and technological conditions, which is called severe waste heat or energy. There are a lot of waste heat resources in HVAC, which can be effectively recycled and used, and can obviously improve the operation efficiency of HVAC. According to the present situation, waste heat recovery and cold heat recovery are two commonly used technologies in heat energy machine. Using the working principle of the heat recovery device, the heat exchange between the air outlet and the listening water is realized. The condensation heat recovery and reuse technology is mainly based on the way of water recycling, which can recycle the waste heat and save energy at the same time, which is beneficial to environmental protection.

\section{Application of hydraulic balancing devices}

Use hydraulic balancing device to ensure the hydraulic balance of air conditioning system. Manual can not achieve hydraulic balance, you can take the hydraulic balance valve to control. In general, hydraulic valves have two kinds of walking and stopping, the actual application of its analysis. For example, when HVAC water waves are large, dynamic hydraulic balance can be used to control and adjust. In other cases, static hydraulic balance valves are generally used.

\section{CONCLUSION}

With the development of The Times and the progress of science and technology, the construction of building HVAC system in the field of national green and energy saving technology has been gradually 
mature, which has played a great role in the gradual promotion of HVAC system. It is extremely important to apply the concept of green energy conservation in the design of building HVAC. Therefore, construction enterprises must vigorously advocate the concept of green energy conservation and persistently promote the promotion and implementation of various advanced energy conservation technologies. This is also the inevitable way for enterprises to achieve healthy and sustainable development under the new situation. Therefore, in the practical energy saving design stage of HVAC, we must make full use of the green concept, so as to obviously improve the energy saving and environmental protection effect of buildings.

\section{REFERENCE}

1. Zhang, Y. (2019). Application analysis of green
Concept in energy Saving design of building HVAC System. Building Materials and Decoration, (36):82-83.

2. Liu, Y. (2019). Discussion on Energy Saving Optimization Strategy of Building HVAC. Building Materials and Decoration, (34):129-130.

3. Zhipeng, L. (2019). Study on energy-saving Design Measures of HVAC System in public Buildings. Residential and Real Estate, (33):67.

4. Hu, Y., \& Liang, T. (2019). Application of green concept in energy-saving design of building HVAC system. Modern Industrial Economy and Information Technology, (8):47-48.

5. Jiang, X., Liming, C., \& Xiaofeng, Q. (2019). Application of green Concept in energy-saving Design of building HVAC system. Guide to science and technology economy, 27(11):70. 